\title{
The signaling role of extracellular ATP in co-culture of Shiraia sp. S9 and Pseudomonas fulva SB1 for enhancing hypocrellin A production
}

\author{
Xin Ping Li, Lu Lu Zhou, Yan Hua Guo and Jian Wen Wang * (D)
}

\begin{abstract}
Background: Adenosine 5'-triphosphate (ATP) plays both a central role as an intracellular energy source, and a crucial extracellular signaling role in diverse physiological processes of animals and plants. However, there are less reports concerning the signaling role of microbial extracellular ATP (eATP). Hypocrellins are effective anticancer photodynamic therapy (PDT) agents from bambusicolous Shiraia fungi. The co-culture of Shiraia sp. S9 and a bacterium Pseudomonas fulva SB1 isolated from Shiraia fruiting bodies was established for enhanced hypocrellin A (HA) production. The signaling roles of eATP to mediate hypocrellin biosynthesis were investigated in the co-culture.

Results: The co-culture induced release of eATP at $378 \mathrm{nM}$ to the medium around $4 \mathrm{~h}$. The eATP release was interdependent on cytosolic $\mathrm{Ca}^{2+}$ concentration and reactive oxygen species (ROS) production, respectively. The eATP production could be suppressed by the $\mathrm{Ca}^{2+}$ chelator EGTA or abolished by the channel blocker $\mathrm{La}^{3+}{ }^{3}$ ROS scavenger vitamin $\mathrm{C}$ and $\mathrm{NADPH}$ oxidase inhibitor diphenyleneiodonium chloride (DPI). The bacterium-induced $\mathrm{H}_{2} \mathrm{O}_{2}$ production was strongly inhibited by reactive blue (RB), a specific inhibitor of membrane purinoceptors, but dependent on the induced $\mathrm{Ca}^{2+}$ influx in the co-culture. On the other hand, the application of exogenous ATP (exATP) at 10-300 $\mu \mathrm{M}$ to Shiraia cultures also promoted fungal conidiation and HA production, both of which were blocked effectively by the purinoceptor inhibitors pyridoxalphosphate-6-azophenyl-2', 4'-disulfonic acid (PPADS) and RB, and ATP hydrolase apyrase. Both the induced expression of HA biosynthetic genes and HA accumulation were inhibited significantly under the blocking of the eATP or $\mathrm{Ca}^{2+}$ signaling, and the scavenge of ROS in the co-culture.

Conclusions: Our results indicate that eATP release is an early event during the intimate bacterial-fungal interaction and eATP plays a signaling role in the bacterial elicitation on fungal metabolites. $\mathrm{Ca}^{2+}$ and ROS are closely linked for activation of the induced ATP release and its signal transduction. This is the first report on eATP production in the fungal-bacterial co-culture and its involvement in the induced biosynthesis of fungal metabolites.
\end{abstract}

Keywords: Shiraia, Pseudomonas fulva SB1, Extracellular ATP, Hypocrellin, Co-culture

*Correspondence: jwwang@suda.edu.cn; bcjwwang@gmail.com College of Pharmaceutical Sciences, Soochow University, Suzhou 215123, China

\begin{abstract}
Background
Adenosine $5^{\prime}$-triphosphate (ATP) is usually recognized as a universal intracellular energy currency to support energy-requiring biochemical reactions in cells, and also function as a signaler outside the plasma membrane for several physiological processes [1]. Animal cells have the ability to produce extracellular ATP (eATP) to
\end{abstract} original author(s) and the source, provide a link to the Creative Commons licence, and indicate if changes were made. The images or other third party material in this article are included in the article's Creative Commons licence, unless indicated otherwise in a credit line to the material. If material is not included in the article's Creative Commons licence and your intended use is not permitted by statutory regulation or exceeds the permitted use, you will need to obtain permission directly from the copyright holder. To view a copy of this licence, visit http://creativecommons.org/licenses/by/4.0/. The Creative Commons Public Domain Dedication waiver (http://creativeco mmons.org/publicdomain/zero/1.0/) applies to the data made available in this article, unless otherwise stated in a credit line to the data. 
regulate growth, immune response, apoptosis, neurotransmission and muscle contraction [2,3]. eATP was found to bind and activate two classes of cell surface receptors, ligand-gated ion channel P2X and G-proteincoupled P2Y receptors to generate second messengers [4]. Emerging evidence indicates eATP is involved in plant growth and development, including the regulation of membrane potential and stomatal movement, growth of root hairs and pollen tubes, gravitropism and abiotic/biotic stress responses [5]. DORN1, plant receptor for eATP, is a lectin receptor kinase, structurally different from animal ATP receptors [6]. eATP initiates the early physiological responses, such as triggering $\mathrm{Ca}^{2+}$ influx, stimulating generation of reactive oxygen species (ROS), and up-regulating expression of mitogen activated protein kinase (MAPK) gene, and later responses such as induced defense gene expression and disease resistance [7]. Although the role of eATP signaling in innate immunity has been well documented in both animals and plants, relatively little is known about eATP signal in microbes. The presence of eATP was observed recently in various human pathogenic bacteria Acinetobacter, Aggregatibacter, Pseudomonas, and Klebsiella [8, 9] and intestinal bacteria [10]. Ding and Tan found that eATP induced dispersal of a periodontal associated bacterium Fusobacterium nucleatum with enhanced virulence to elicit inflammation in periodontal disease [11]. eATP was reported as a damage-associated molecular pattern (DAMP) to induce the influx of cytosolic free calcium $\left(\left[\mathrm{Ca}^{2+}\right]_{\text {cyt }}\right)$ and activate the MAPK Tmk1 for hyphal regeneration of a filamentous fungus Trichoderma atroviride under mechanical damage [12,13]. Although there was a report of exogenous ATP (exATP) to enhance tautomycetin in Streptomyces griseochromogenes [14], less reports have been found concerning the signaling role of eATP on the biosynthesis of microbial secondary metabolites.

Hypocrellins, the main perylenequinones of Shiraia fungi, are new non-porphyrin photosensitizer in photodynamic therapy (PDT) for cancers [15] and immunodeficiency virus [16]. Our previous study revealed that some eliciting strategies including light/dark shift (24: $24 \mathrm{~h}, 200 \mathrm{~lx})$ and ultrasound exposure $\left(0.28 \mathrm{~W} / \mathrm{cm}^{2}\right.$ at $40 \mathrm{kHz}$ ) were successful to enhance hypocrellin production of Shiraia [17, 18]. In our previous study [19], a bacterium Pseudomonas fulva SB1 from Shiraia fruiting bodies was found to increase hypocrellin production significantly. The established co-culture system for Shiraia with $P$. fulva SB1 presented a higher production of hypocrellin A (HA) $325.87 \mathrm{mg} / \mathrm{L}$, about 3.20 -fold of that in axenic culture [20]. Furthermore, we found the expression of ATP-binding cassette $(A B C)$ of Shiraia sp. S9 was up-regulated, about 3.1-fold of the mono-culture control.
More evidence supported that $\mathrm{ABC}$ is the one of carriers for the active transport of ATP from intracellular stores into the extracellular matrix $[21,22]$. On the other hand, the signaling of ROS and $\mathrm{Ca}^{2+} /$ calmodulin (CaM) have been validated during the application of Triton X-100 and fungal elicitor on Shiraia for hypocrellin production $[23,24]$. Since the increased levels of $\left[\mathrm{Ca}^{2+}\right]_{\mathrm{cyt}}$ and ROS have been proved the early signaling steps of eATP in both animal and plant cells [7], we hereby hypothesized that eATP may be involved in the induced responses during the bacterial-fungal interaction. Recently, bacterial-fungal co-culture which mimics the natural microbe communities is becoming an effective strategy to expand microbial chemodiversity or improve metabolite production. The microbial metabolites (259 compounds) induced in co-cultures are subdivided by Arora et al. into 9 significant clusters in three groups of "non-nitrogenated compounds", "non-alkaloidic nitrogenated compounds" and "alkaloidic compounds" [25]. The induction by co-culture was revealed to be the result of the microbial biotransformation [26], activation of cryptic biosynthetic pathways [27] or the increased histone acetylation [28]. However, little information is available regarding chemical signals for the compound induction by co-culture. As a follow-up to our efforts to elucidate the signaling events on eliciting hypocrellin biosynthesis $[18,20$, 24], we examined the changes of eATP in the co-culture of Shiraia sp. S9 with the bacterium P. fulva SB1. We also explored the relationship between eATP and induced ROS or $\mathrm{Ca}^{2+}$ influx, and their mediation on hypocrellin biosynthesis. Understanding the signaling role of eATP in the bacterium-host interaction may provide new insight in the induction mechanisms and lead to the development of novel co-culture strategy for fungal metabolite production.

\section{Results \\ eATP release in the co-culture}

The fungal-bacterial confrontation assay (Fig. 1a) was used to investigate the effect of the bacterium $P$. fulva SB1 on the hypocrellin accumulation of host fungus Shiraia sp. S9 in PDA medium. After 2-6 days of co-culture, the secretion of red pigments of mycelia of $\mathrm{S} 9$ was observed (Fig. 1b). The total HA production in shake flask culture was measured to $263.25 \mathrm{mg} / \mathrm{L}$, a 2.48 -fold of mono-culture of S9 on day 8 (Fig. 1c). A significant increase of the eATP was observed after $15 \mathrm{~min}$ and its concentration peaked at $378 \mathrm{nM}$ around $4 \mathrm{~h}$ (Fig. 1d). To determine the source of eATP production, we measured eATP release in the fungal culture $(\mathrm{F})$ treated with live bacterium (B), the bacterial broth extracts (BBE), crude bacterial polysaccharide (BPS) as well as heat-killed bacterium (DB) (Fig. 1e). The eATP concentration was increased only by 

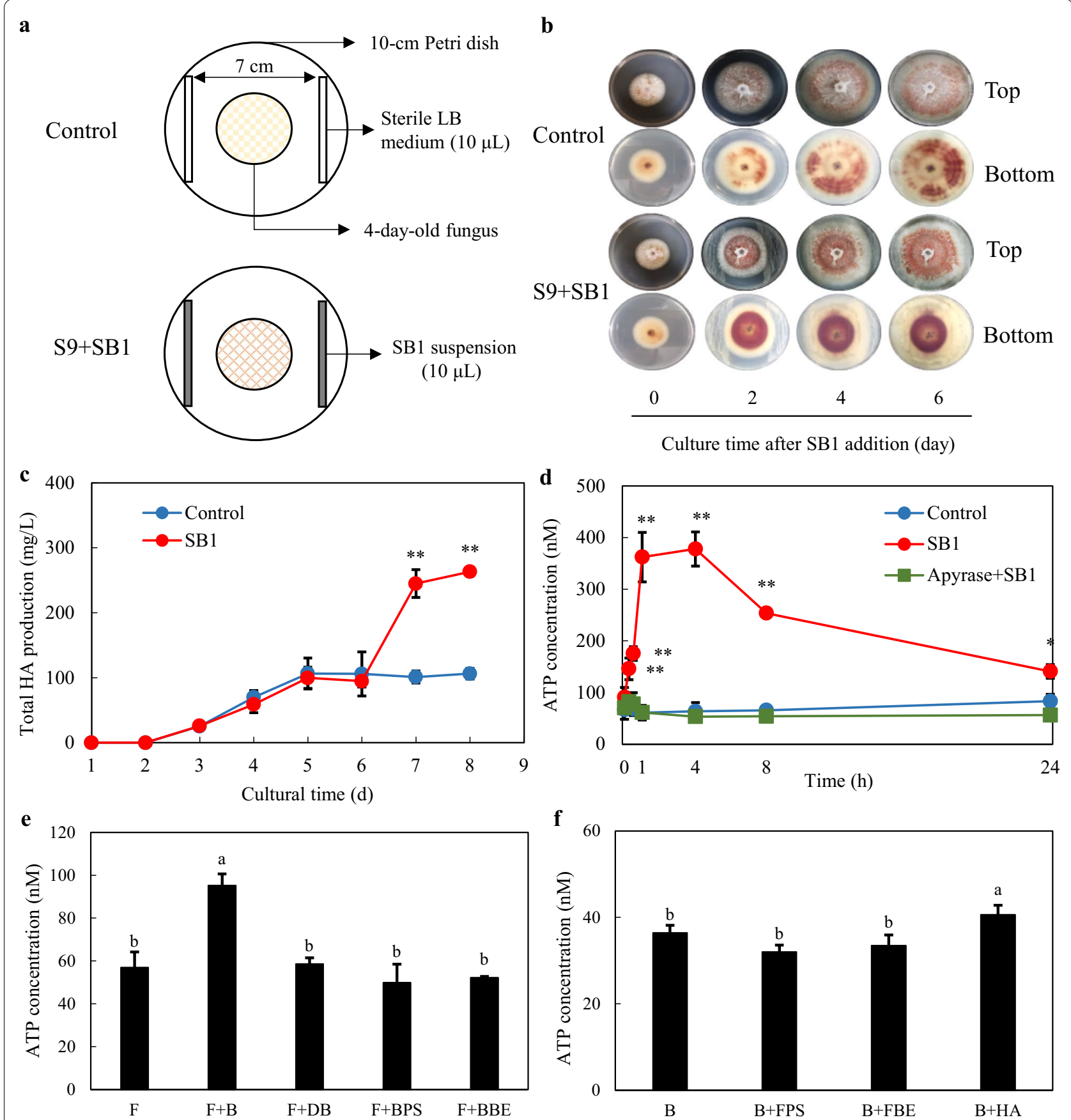

Fig. 1 Hypocrellin A (HA) production and ATP release in the co-culture of Shiraia sp. S9 and P. fulva SB1. a Scheme of the in vitro dual culture plate confrontation assay. $\mathbf{b}$ The effects of live SB1 on the growth and red pigments secretion of S9 in PDA plate. The 4-day-old fungal colony was treated with SB1 for 2-6 days. The bacterial suspension $(10 \mu \mathrm{L})$ was streaked in two parallel straight lines, approximately $7 \mathrm{~cm}$ apart from each other. The culture was maintained on PDA at $28^{\circ} \mathrm{C}$. c The total HA production of S9 in the co-culture. The co-culture was maintained in 150-mL flask containing $50 \mathrm{~mL}$ of the liquid medium at $150 \mathrm{rpm}$ and $28^{\circ} \mathrm{C}$ for $8 \mathrm{~d}$. d ATP release in the co-culture. The 6-day-old fungal mycelia were treated with SB1 (400 cells $/ \mathrm{mL})$ and incubated at $150 \mathrm{rpm}$ and $28^{\circ} \mathrm{C}$. Apyrase at $2 \mathrm{U} / \mathrm{mL}$ was added to the culture at $1 \mathrm{~h}$ prior to the addition of SB1. e The released ATP in the fungal culture with live SB1 (B, 400 cells $/ \mathrm{mL})$, heat-killed SB1 (DB, 400 cells/mL), the crude bacterial polysaccharide (BPS) and bacterial broth extracts (BBE) at $100 \mathrm{mg} / \mathrm{mL}$ for $1 \mathrm{~h}$. f The released ATP in bacterial culture with fungal polysaccharides (FPS) and the ethyl acetate extracts (FBE) at $100 \mathrm{mg} / \mathrm{mL}$ and $\mathrm{HA}(5 \mathrm{mg} / \mathrm{mL})$ treatment for $1 \mathrm{~h}$. Values are mean $\pm S D$ from three independent experiments $\left({ }^{*} p<0.05\right.$ and ${ }^{* *} p<0.01$ vs. control). Different letters above the bars mean significant differences $(p<0.05)$ 
live bacterium ( $F+B$ in Fig. 1e), whereas the treatment of bacterial extracts (BBE and BPS) did not alter the eATP concentration. Conversely, we measured the eATP production in bacterial cultures treated by fungal polysaccharides (FPS) or fungal broth extracts (FBE) as well as $\mathrm{HA}$ at $5 \mathrm{mg} / \mathrm{mL}$ (Fig. 1f). The eATP concentration was only improved slightly by HA. These results suggested that the release of eATP depended on the presence of live bacterium and fungus in the co-culture.

\section{eATP-induced fungal $\mathrm{HA}$ production and conidiation}

exATP at $10-300 \mu \mathrm{M}$ was applied to the solid culture of S9 and the secretion of red pigments was increased (Fig. 2a). In a liquid culture, both the intracellular and extracellular HA was enhanced by exATP $(50-200 \mu \mathrm{M})$ and dose-dependent (Fig. 2b). To verify the effect of ATP, both the purinoceptor inhibitor pyridoxalphosphate6-azophenyl-2', 4'-disulfonic acid (PPADS) or reactive blue (RB) at $10 \mu \mathrm{M}$, and an ATP hydrolyzer apyrase at 2
$\mathrm{U} / \mathrm{mL}$ were used to block eATP response in the co-culture. As shown in Fig. 2c, the intracellular and extracellular HA were decreased significantly by apyrase or the purinoceptor inhibitors in the co-culture. On the other hand, we conducted an additional control experiment with the non-hydrolyzable form of ATP $(\mathrm{ATP} \gamma \mathrm{S})$ and ATP derivatives (ADP and AMP) to induce HA production (Fig. 2d). ATP $\gamma$ S increased HA production to a similar level compared with that induced by exATP while ADP or AMP induced much lower levels of HA increase, indicating that ATP hydrolysis is not required for the elicitation on HA production.

Simultaneously, we found that the number of pycnidium and the conidia concentration of S9 was increased dose-dependently after exATP treatment at 100, $300 \mu \mathrm{M}$, respectively (Fig. 3a, b). In the fungal-bacterial confrontation assay, live bacterium SB1 increased the fungal conidiation by $134.1 \%$ (SB1 in Fig. 3c). Both the treatment of the purinoceptor inhibitors and ATP hydrolyzer apyrase

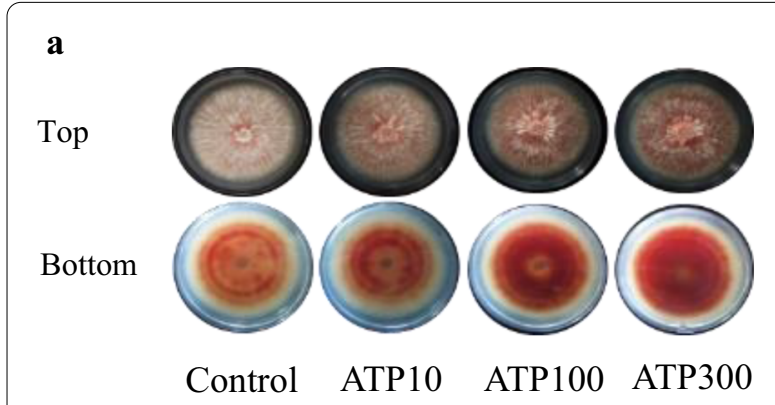

c

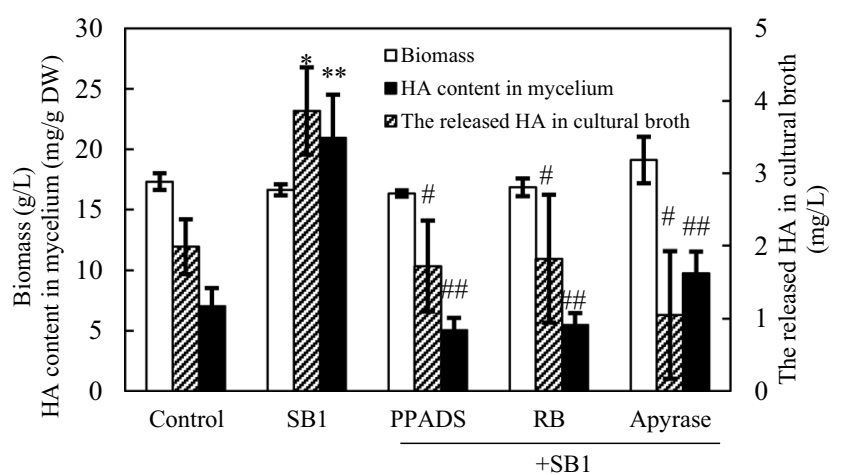

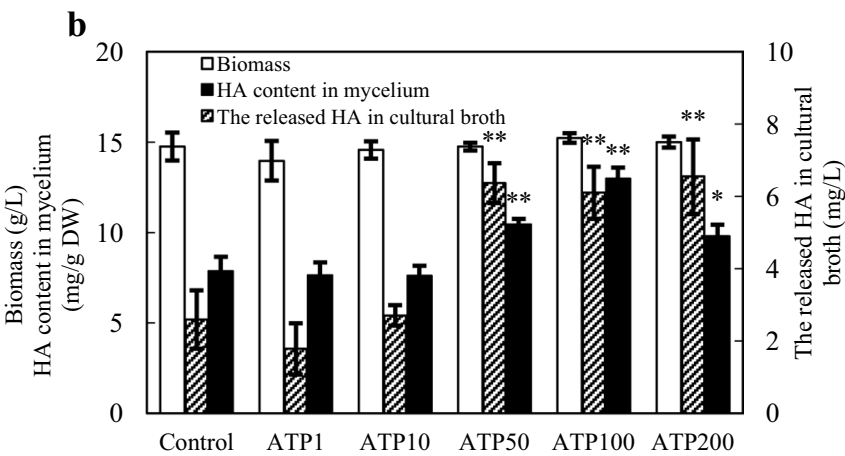

d

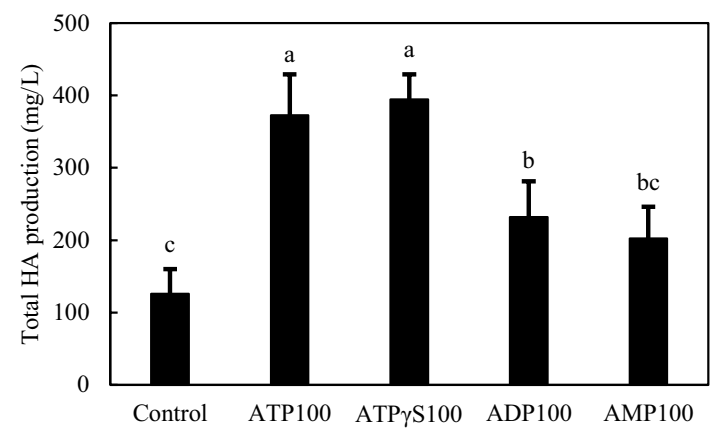

Fig. 2 The effect of ATP on hypocrellin A (HA) production of Shiraia sp. S9. a The effects of exogenous ATP (exATP) on the growth and red pigments secretion of Shiraia sp. S9 in PDA plate. S9 was treated with exATP and incubated at $28^{\circ} \mathrm{C}$ for 10 days. $\mathbf{b}$ The effects of exATP on HA production in submerged culture. exATP was added on day 6 during the 8-day-culture of S9. c The effect of purinoceptor inhibitors and apyrase on SB1-induced HA production. The 6-day-old fungal mycelia were incubated with inhibitors pyridoxalphosphate-6-azophenyl-2', 4'-disulfonic acid (PPADS) and reactive blue (RB) at $10 \mu \mathrm{M}$ and apyrase $(2 \mathrm{U} / \mathrm{mL}$ ) for $1 \mathrm{~h}$ before SB1 addition and cultured for additional 2 days. $\mathbf{d}$ The effects of ATP analog (ATPYS) and derivatives (ADP and AMP) on HA production in submerged culture. exATP, ATP $\mathrm{S}$, ADP and AMP were added respectively at $100 \mu M$ on day 6 during the 8-day-culture of S9. Values are mean \pm SD from three independent experiments $\left({ }^{*} p<0.05\right.$ and ${ }^{* *} p<0.01$ vs. control, ${ }^{\#} p<0.05$ and $\# p<0.01$ vs. SB1 treatment). Different letters above the bars mean significant differences $(p<0.05)$ 


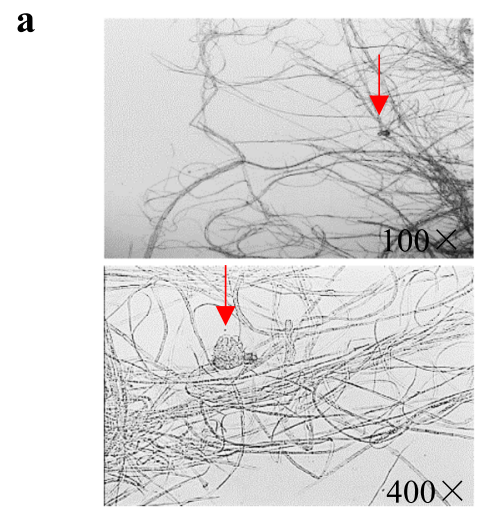

Control

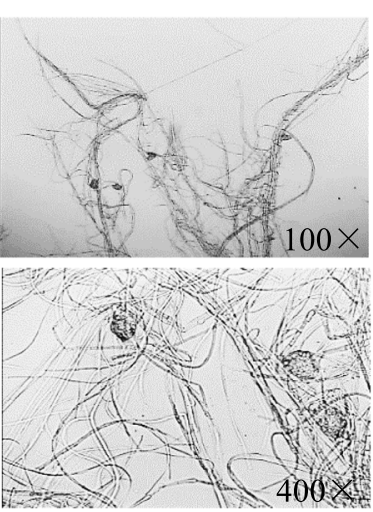

ATP10
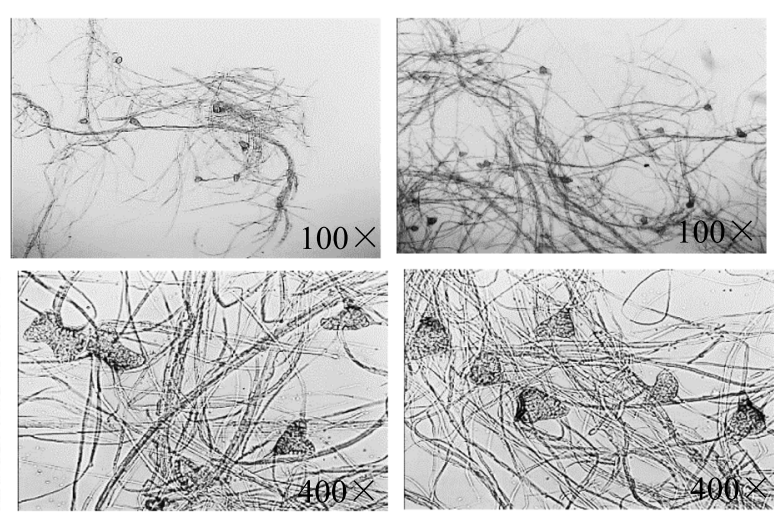

ATP100

ATP300

$\mathbf{b}$

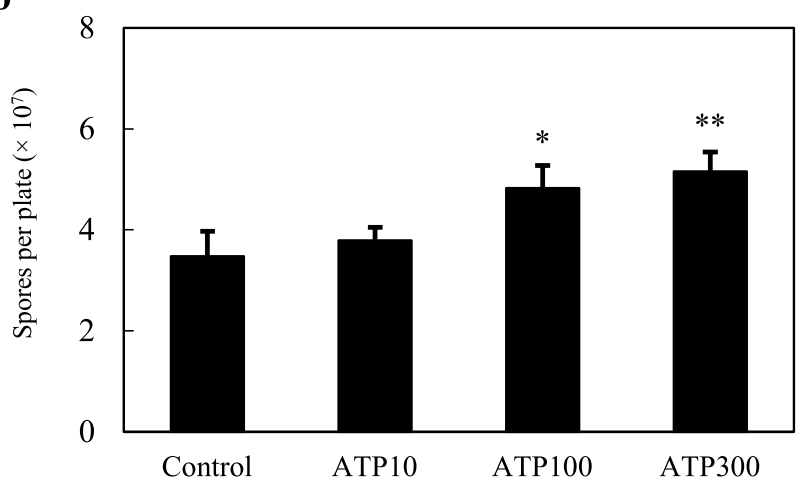

c

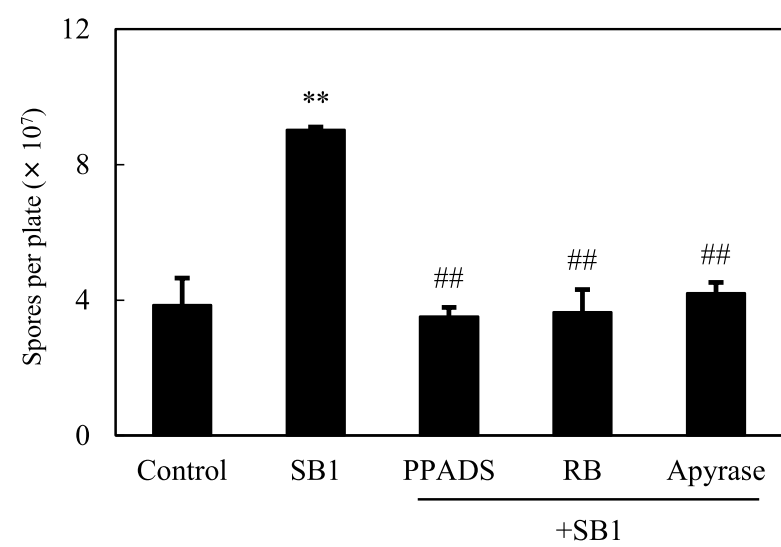

Fig. 3 The effect of ATP on aerial mycelial growth $\mathbf{a}$ and conidiation $\mathbf{b}$ of Shiraia sp. S9. in PDA plate. Arrow (red) indicates pycnidium. cThe effect of purinoceptor inhibitors and apyrase on SB1-induced fungal conidiation. S9 was treated with pyridoxalphosphate-6-azophenyl-2', $4^{\prime}$-disulfonic acid (PPADS) and reactive blue (RB) at $10 \mu \mathrm{M}$ or apyrase $(2 \mathrm{U} / \mathrm{mL})$ for $30 \mathrm{~min}$, then placed in the center of $10-\mathrm{cm}$ PDA plate. The culture was maintained on PDA at $28^{\circ} \mathrm{C}$ for $8 \mathrm{~d}$. Values are mean \pm SD from three independent experiments $\left({ }^{*} p<0.05\right.$ and ${ }^{* *} p<0.01$ vs. control, ${ }^{\#} p<0.05$ and ${ }^{\# \#} p<0.01$ vs. SB1 treatment)

significant suppressed the induced conidiation (Fig. 3c), indicating that the SB1-induced conidiation was modulated by eATP signal.

\section{Effect of eATP on SB1-induced ROS generation}

As shown in Fig. 4a, the green fluorescence detected by 2, 7-dichlorodihydrofluorescein diacetate (DCFH-DA) in fungal mycelia was found after SB1 addition within $2 \mathrm{~h}$. The fluorescence intensity reached to a maximum level (9.32-fold of control) around $12 \mathrm{~h}$ (Fig. 4b). The SB1induced green fluorescence was almost completely suppressed by PPADS $(10 \mu \mathrm{M}), \mathrm{RB}(10 \mu \mathrm{M})$ or apyrase (2 U/ $\mathrm{mL}$ ) (Fig. 4c). The $\mathrm{H}_{2} \mathrm{O}_{2}$ content in SB1 treated mycelia reached to a peak level of $17.65 \mu \mathrm{mol} / \mathrm{g}$ fresh weight (FW) at $12 \mathrm{~h}$, which was 2.48 -fold of the control level (Fig. $4 \mathrm{~d}$ ). But $\mathrm{H}_{2} \mathrm{O}_{2}$ contents in fungal mycelia were decreased by $55.3 \%, 54.7 \%$ and $59.9 \%$ by PPADS, RB and apyrase at $12 \mathrm{~h}$, respectively (Fig. $4 \mathrm{~d}$ ). These results suggested that the induction of ROS generation by SB1 was dependent on eATP release in the co-culture.

\section{Effect of eATP on SB1-induced $\mathrm{Ca}^{2+}$ influx}

The $\mathrm{Ca}^{2+}$ accumulation in SB1 treated fungal mycelia was directly observed by using the fluorescent cell-permeant calcium indicator Fluo-3 AM. The greener fluorescence of fungal mycelia was observed after the SB1 addition (Fig. 5). The enhanced fluorescent signal was detected within $15 \mathrm{~min}$ and rose to a peak (2.31-fold of control) around $30 \mathrm{~min}$, and then dropped back to the initial control level after $30 \mathrm{~min}$ (Fig. 5a, b). The green fluorescence was blocked by PPADS, RB and apyrase (Fig. 5c) and the induced-elevation of cytosolic free calcium was decreased by $66.7 \%, 61.0 \%$ and $66.5 \%$, separately after SB1 addition for $30 \mathrm{~min}$ (Fig. 5d). These results indicated that SB1-induced $\mathrm{Ca}^{2+}$ influx was dependent on eATP in the co-culture. 


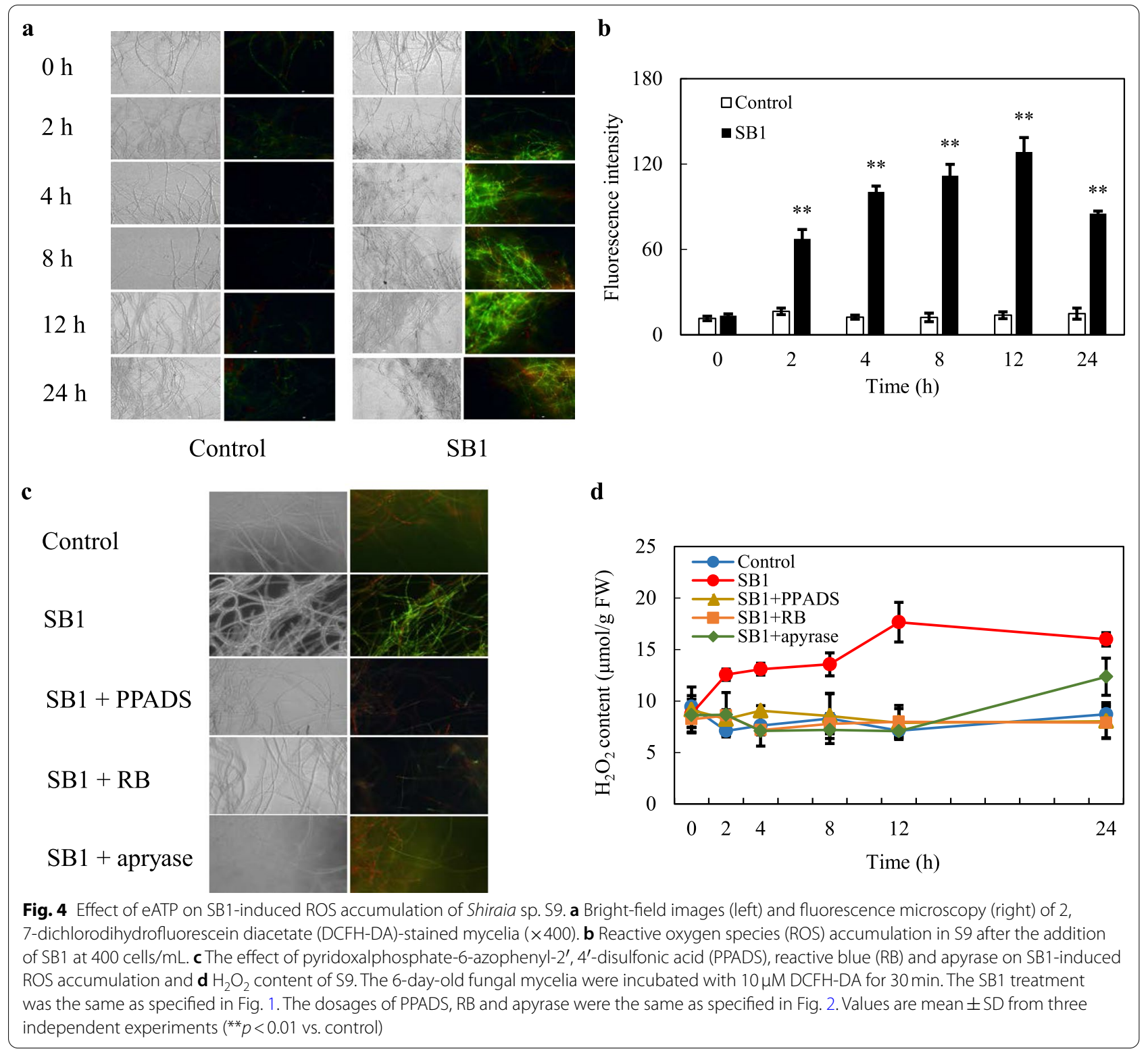

\section{Dependence of eATP, ROS and $\mathrm{Ca}^{2+}$}

To further investigate on the interaction among SB1induced $\mathrm{ROS}$ and $\mathrm{Ca}^{2+}$, vitamin $\mathrm{C}(\mathrm{Vc}, 0.1 \mathrm{mM})$ and $\mathrm{NADPH}$ oxidase inhibitor diphenyleneiodonium chloride (DPI, $5 \mu \mathrm{M}$ ) were used to inhibit ROS generation, while $\mathrm{Ca}^{2+}$ chelator (EGTA at $5 \mathrm{mM}$ ) and membrane channel blocker $\left(\mathrm{La}^{3+}\right.$ at $\left.2 \mathrm{mM}\right)$ were used to inhibit the $\mathrm{Ca}^{2+}$ influx (Fig. 6). When SB1-induced ROS was eliminated by Vc and DPI, there were not any notable changes of $\mathrm{Ca}^{2+}$ in fluorescent signal and its intensity $(\mathrm{SB} 1+\mathrm{Vc}$ or + DPI vs. SB1 in Fig. 6a, b). However, the ROS production in mycelia were reduced after $\mathrm{Ca}^{2+}$ signaling was blocked by EGTA or $\mathrm{La}^{3+}\left(\mathrm{SB} 1+\mathrm{EGTA}\right.$ or $+\mathrm{La}^{3+}$ vs. SB1 in Fig. 6c, d). The results suggested that the ROS production may occur downstream of $\mathrm{Ca}^{2+}$ influx in the co-culture. Furthermore, the eATP production in the coculture was effectively suppressed to control level after ROS inhibition by Vc and DPI, or blocking $\mathrm{Ca}^{2+}$ influx by $\mathrm{La}^{3+}$ (Fig. 7). While pre-treatment with EGTA before SB1 addition only partially decreased the eATP release. These results indicated that $\mathrm{Ca}^{2+}$ influx and ROS generation may also contribute to the regulation of eATP efflux in the co-culture. 


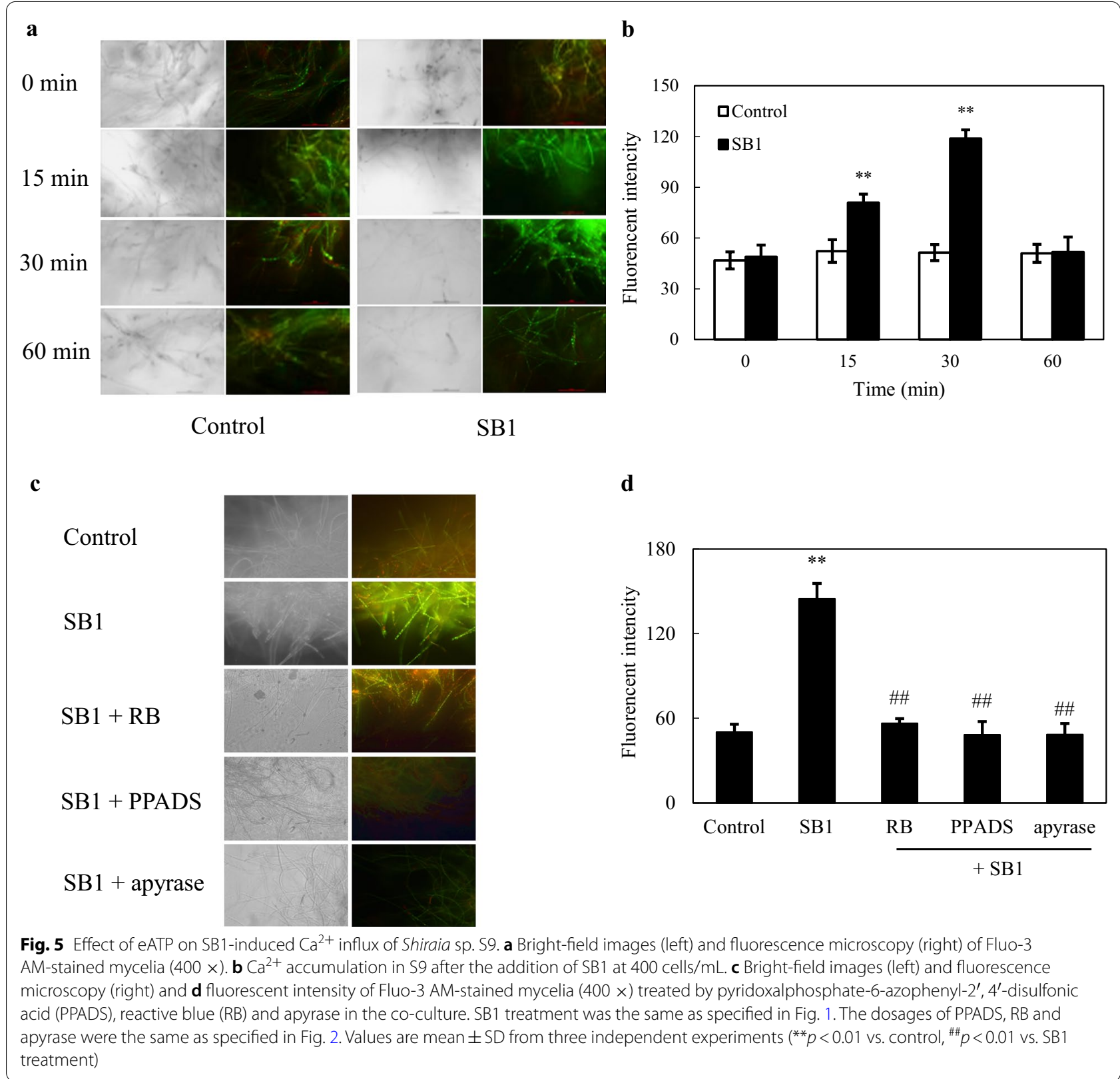

Effect of eATP on expressions of biosynthetic genes for HA To investigate on the mechanism of eATP on SB1induced HA production, the expressions of eight genes for HA biosynthesis were analyzed by qRT-PCR after $24 \mathrm{~h}$ of co-culture (Fig. 8). The genes encoding polyketide synthase $(P K S)$, FAD/FMN-dependent oxidoreductase $(F A D)$, monooxygenase (Mono), multicopper oxidase $(M C O)$, $O$-methyltransferase (Omef), zinc finger transcription factor $(Z F T F)$, major facilitator superfamily $(M F S)$ and ATP-binding cassette transporter $(A B C)$ were all up-regulated, about 2.45-, 1.71-, 1.94-, 2.97-, 2.53-, 2.91-, 2.47- and 4.94-fold of control, respectively.
Simultaneously, exATP at $100 \mu \mathrm{M}$ also increased their expressions with the similar trend of live SB1. However, after eATP release in co-culture was hydrolyzed by apyrase, the expression of $P K S$ was dropped back to control level, whereas $F A D$, Mono, Omef and $A B C$ expressions were down-regulated (4.52-6.66-fold of control).

To further investigate the influence of eATP, ROS and $\mathrm{Ca}^{2+}$ influx on $\mathrm{HA}$ biosynthesis in co-culture, the exogenous donors (exATP, $\mathrm{H}_{2} \mathrm{O}_{2}$ and $\mathrm{Ca}^{2+}$ ) or specific inhibitors ( $\mathrm{RB}, \mathrm{Vc}$ and $\mathrm{La}^{3+}$ ) were used (Fig. 9). After the addition of exATP at $100 \mu \mathrm{M}, \mathrm{H}_{2} \mathrm{O}_{2}$ at $1 \mathrm{mM}$ or $\mathrm{Ca}^{2+}$ at $2 \mathrm{~g} / \mathrm{L}$ for $24 \mathrm{~h}$, significant increase in the transcript 


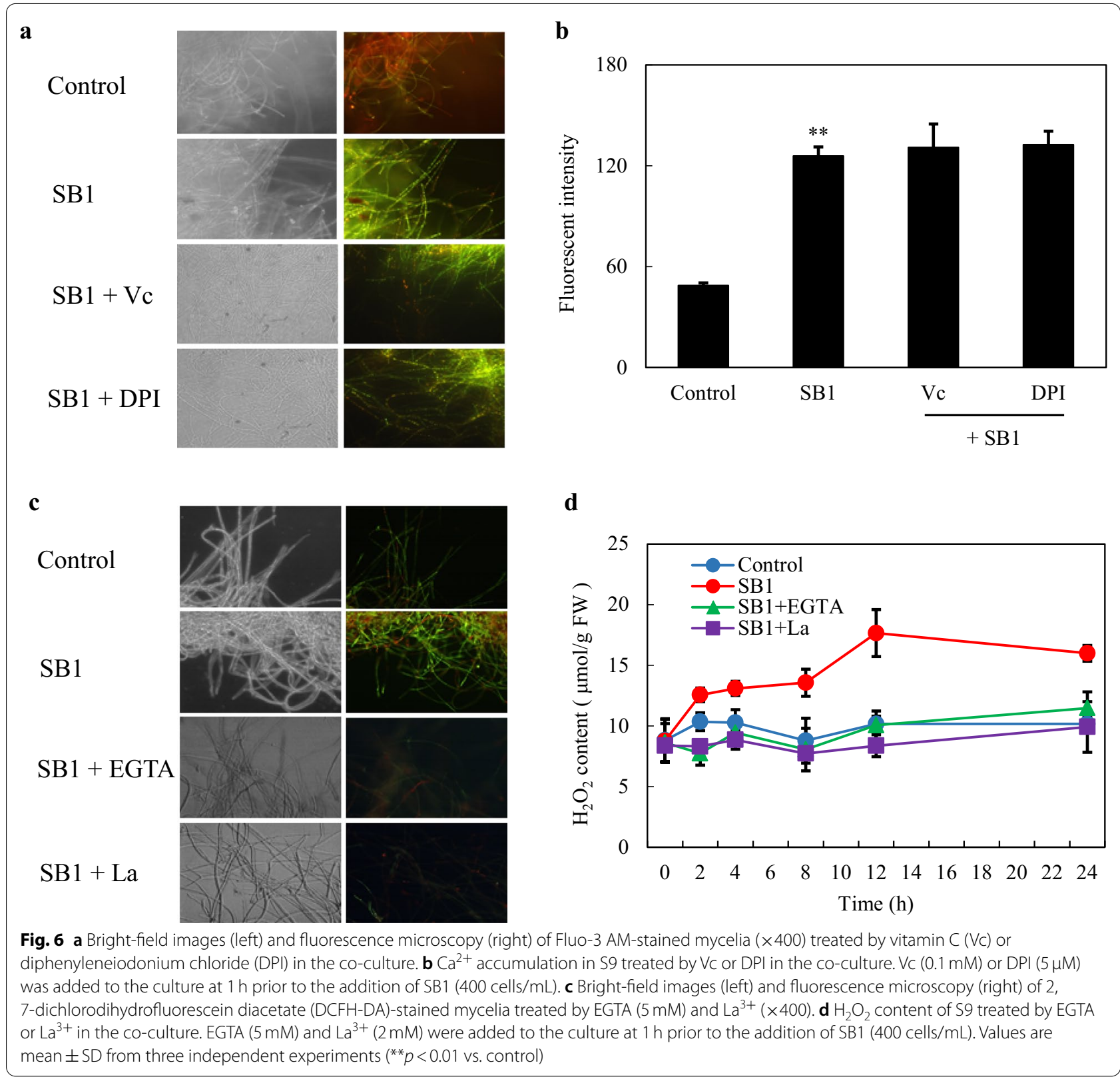

level of PKS (145.2-453.1\%), FAD (111.6-166.9\%), MFS (23.0-160.8\%) and Omef (165.6-228.9\%) were observed respectively. On the other hand, the enhanced expressions of these genes induced by live SB1 were inhibited after $\mathrm{Ca}^{2+}$, ROS, eATP signaling was blocked by $\mathrm{La}^{3+}, \mathrm{Vc}$ or $\mathrm{RB}$, respectively $\left(\mathrm{SB} 1+\mathrm{La}^{3+},+\mathrm{Vc}\right.$ or $+\mathrm{RB}$ vs. $\mathrm{SB} 1$ in Fig. 9). Simultaneously, HA contents in mycelium were all increased by $68.9 \%, 91.4 \%, 20.1 \%$ and $34.9 \%$ after SB1, exATP, $\mathrm{H}_{2} \mathrm{O}_{2}$ and $\mathrm{Ca}^{2+}$ treatment, respectively (Fig. 10). The released $\mathrm{HA}$ in cultural broth were increased by $154.7 \%$ and $183.0 \%$ by SB1 and exATP, respectively. However, both the intracellular and extracellular HA productions were significantly decreased by $\mathrm{La}^{3+}, \mathrm{Vc}$ or $\mathrm{RB}$ in the co-culture (SB1+ $\mathrm{La}^{3+},+\mathrm{Vc}$ or $+\mathrm{RB}$ vs. $\mathrm{SB} 1$ in Fig. 10). Taken together, these results suggested strongly that the SB1-induced HA biosynthesis was mediated by eATP, $\mathrm{ROS}$ and $\mathrm{Ca}^{2+}$ signaling.

\section{Discussion}

eATP has been recognized as an important signaling molecule that affects a broad range of biological processes in multicellular organisms like plants and animals [1]. Recent studies show that bacteria, yeasts and fungi can also release ATP into the extracellular compartment 


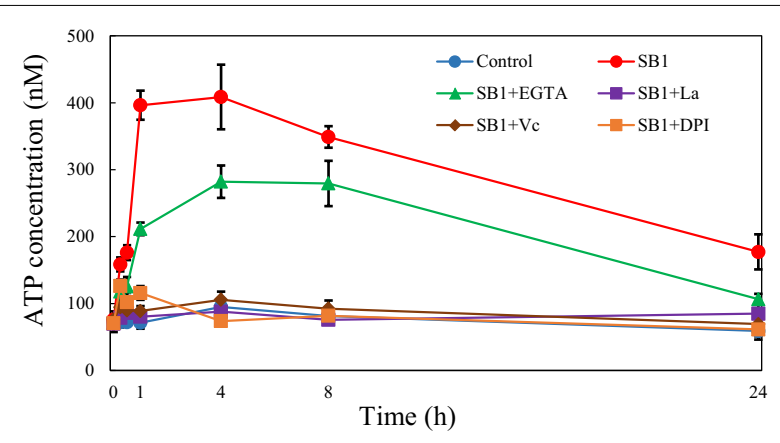

Fig. 7 The SB1-induced ATP release and its dependence on $\mathrm{Ca}^{2+}$ and ROS in Shiraia sp. S9. The SB1 treatment was the same as specified in Fig. 1. The dosages of vitamin C (Vc), diphenyleneiodonium chloride (DPI), EGTA and $\mathrm{La}^{3+}$ were the same as specified in Fig. 6. Values are mean \pm SD from three independent experiments

or the culture medium. An earlier report by Ivanova et al. (2006) showed some Gram-negative $\alpha$-proteobacteria and $\gamma$-proteobacteria could release eATP from micromolar to millimolar concentrations [29]. Some Enterococcus strains from mice and human feces, urine, and skin could secrete eATP at $1-3 \mu \mathrm{M}$ in the cultural supernatant, but two bacterial strains (Escherichia coli and Staphylococcus aureus) failed to show eATP secretion [30]. eATP production was found to be dependent on bacterial glycolysis, respiration and growth phase $[8,31]$. Although eATP released by periodontal associated bacteria or commensal bacteria in the intestines has been reported to be involved in the periodontal or intestinal inflammation [11, 32], the purpose and significance of bacterial eATP is still poorly understood. Fungi such as Candida albicans and yeast Saccharomyces cerevisiae were found to secret ATP in the presence of glucose [33] or against the treatment of antifungal salivary histatins [34]. eATP from $S$. cerevisiae was elevated during growth and acted as the intercellular signal to induce and synchronize yeast sporulation [35]. Medina-Castellanos et al. (2014; 2018) demonstrated a filamentous fungus $T$. atroviride could regulate wound responses, conidiation and hyphal regeneration by eATP $[12,13]$. In this study, we found that eATP was released in co-culture of a bambusicolous fungus Shiraia sp. S9 and a fruiting body-associated bacterium P. fulva SB1 to $146-378 \mathrm{nM}$ during $4 \mathrm{~h}$, and fully suppressed by adding apyrase at $2 \mathrm{U} / \mathrm{mL}$ for the hydrolysis of ATP (Fig. 1d). These results suggested the production of eATP was triggered by the co-culture. This is the first report on eATP production in the fungal-bacterial co-culture.

In our study, the treatment of BBE, BPS and DB exhibited no capacity to induce eATP production in the fungal culture (Fig. 1e). The effect of live bacteria and cell-free bacterial broth on the fungus Arthrinium c.f. saccharicola was investigated [36]. The fungus growth was inhibited by live bacterium Pseudoalteromonas piscida whereas the cell-free culture broth of the bacterium

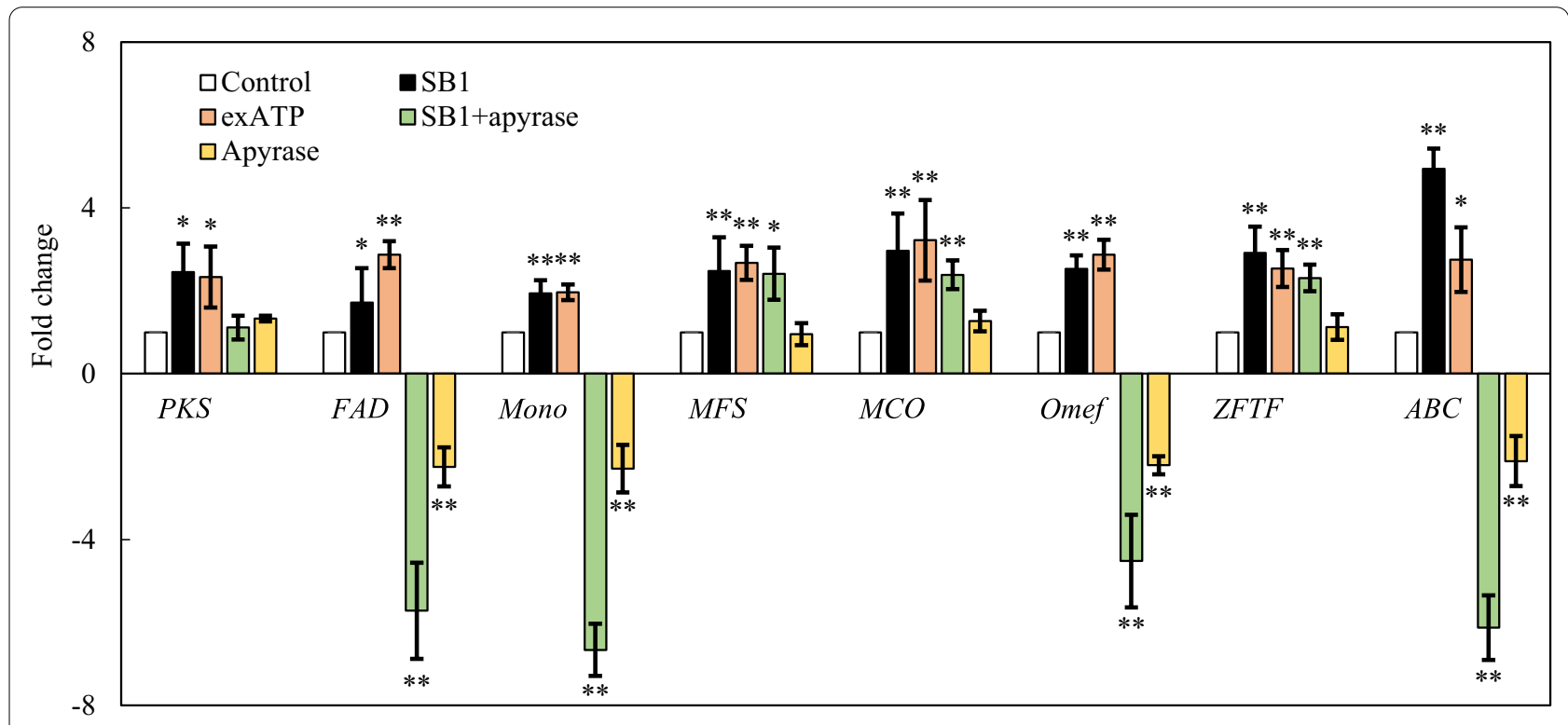

Fig. 8 Effect of eATP on the expressions of hypocrellin A (HA) biosynthetic genes of Shiraia sp. S9. The co-culture method was the same as specified in Fig. 1. Exogenous ATP (exATP) and apyrase treatment and their concentration were the same as specified in Fig. 2. The culture was maintained in 150 -mL flask containing $50 \mathrm{~mL}$ of the liquid medium at $150 \mathrm{rpm}$ and $28^{\circ} \mathrm{C}$ for 8 days. Values are mean $\pm S D$ from three independent experiments $\left({ }^{*} p<0.05\right.$ and ${ }^{* *} p<0.01$ vs. control) 


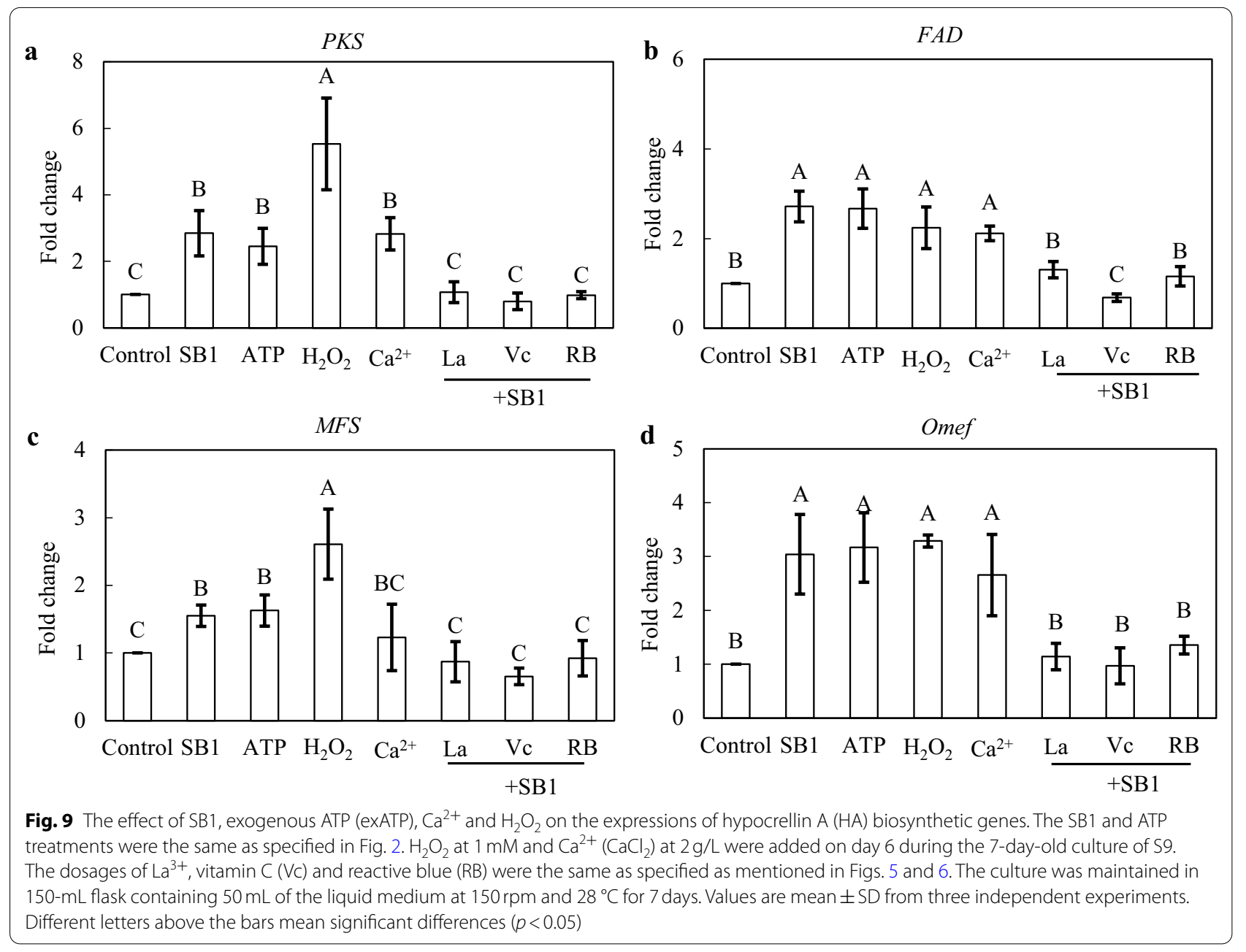

induced the changes of fungal metabolite profiles and improved the antibacterial activity of the fungus. The signaling molecules produced by the bacterium may contribute to the enhanced fungal bioactivity. Furthermore, Schroeckh et al. (2009) demonstrated the intimate physical contact of Aspergillus nidulans and S. hygroscopicus in the co-culture was required for induction of silent polyketide metabolism in Aspergillus [27]. Those results support that both diffusible signaling molecules from the bacterium and intimate bacterial contact can have physiological roles during the co-cultures. In the present study, eATP production in the bacterial culture was also not elicited by FBE and FPS (Fig. 1f), indicating that the live bacterium and fungus were essential for the secretion of eATP to the medium. In our previous study on the coculture of Shiraia sp. S9 and P. fulva SB1 [20], both the direct physical contact and fragmentation of hyphae of Shiraia sp. S9 were observed. In plants, eATP acts as DAMP signal during herbivory, mechanical damage or pathogen attack [5]. The increased eATP levels were also found in damaged hyphae of $T$. atroviride by using a scalpel [12]. Thus, further studies are needed to verify whether eATP is DAMP signal associated with intimate bacterial-fungal interactions in the co-culture.

In the present study, fungal conidiation was activated after the co-cultivation with the bacterium SB1 (Fig. 3c). The concentration of conidia was increased from $3.47 \times 10^{7}$ to $5.16 \times 10^{7}$ spores/plate after exATP treatment $(300 \mu \mathrm{M})($ Fig. 3b). The SB1-induced fungal conidiation in co-culture was completely blocked by nucleotide receptor antagonists (PPADS and RB at $10 \mu \mathrm{M}$ ) and ATP hydrolase (apyrase at $2 \mathrm{U} / \mathrm{mL}$ ) (Fig. 3c). These results were consistent with the induced conidiation found in $T$. atroviride in response to mechanical damage by a scalpel $[12,13]$. Our results demonstrated that exATP $(10-300 \mu \mathrm{M})$ promoted significantly the secretion of HA in PDA plate (Fig. 2a) and the HA production in shake flasks (Fig. 2b). Furthermore, the suppression of live bacterium-induced HA production by nucleotide receptor antagonist RB or ATP hydrolase apyrase was observed in 


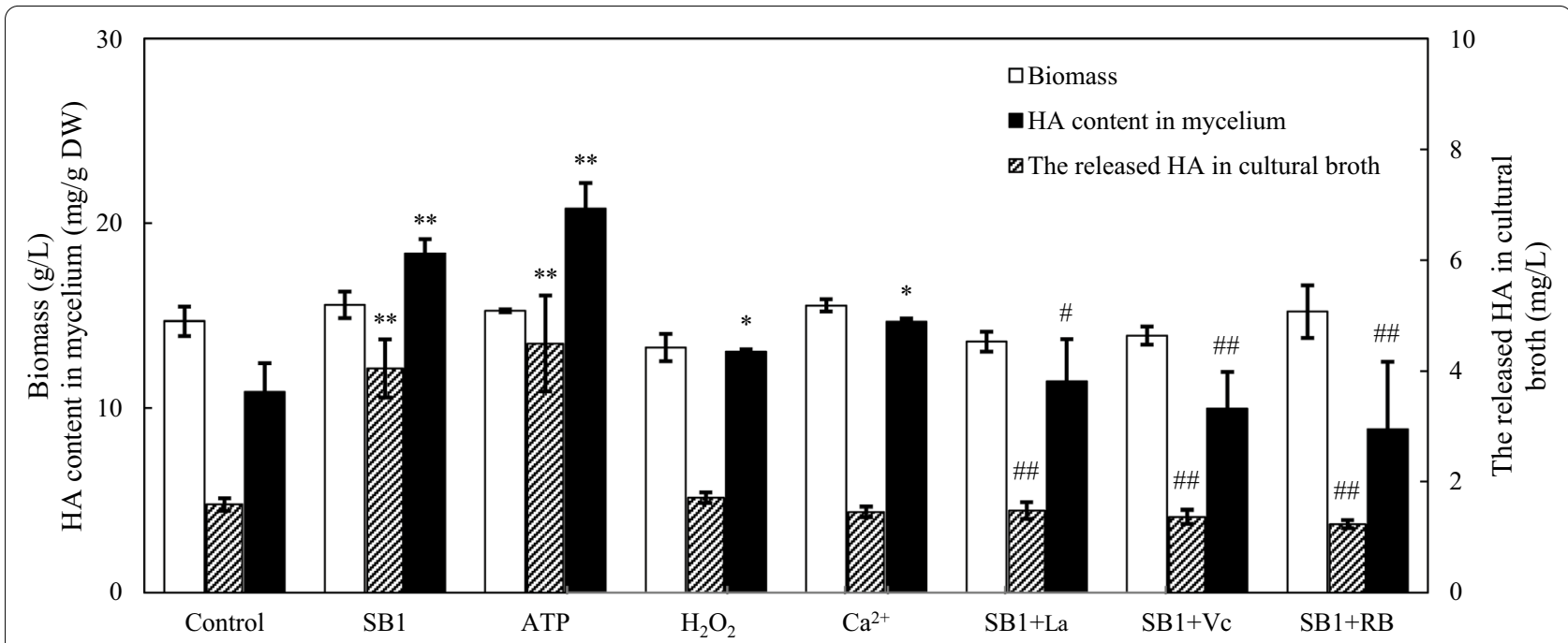

Fig. 10 Effect of SB1, ATP, $\mathrm{Ca}^{2+}$ and $\mathrm{H}_{2} \mathrm{O}_{2}$ on hypocrellin $\mathrm{A}(\mathrm{HA})$ production of Shiraia sp. S9. The SB1 and ATP treatments were the same as specified in Fig. 7. $\mathrm{H}_{2} \mathrm{O}_{2}$ at $1 \mathrm{mM}$ and $\mathrm{Ca}^{2+}\left(\mathrm{CaCl}_{2}\right)$ at $2 \mathrm{~g} / \mathrm{L}$ were added on day 6. The dosages of $\mathrm{La}^{3+}$, vitamin $\mathrm{C}(\mathrm{Vc})$ and reactive blue (RB) were the same as specified in Figs. 5 and 6 . The culture was maintained in 150-mL flask containing $50 \mathrm{~mL}$ of the liquid medium at $150 \mathrm{rpm}$ and $28^{\circ} \mathrm{C}$ for 8 days. Values are mean \pm SD from three independent experiments ( ${ }^{*} p<0.05$ and ${ }^{* *} p<0.01$ vs. control, ${ }^{\#} p<0.05$ and ${ }^{\# \#} p<0.01$ vs. SB1 treatment)

Fig. 2c. Therefore, taken together, our results suggested the existence of eATP receptors and the regulatory role of eATP on fungal conidiation and HA biosynthesis in the co-culture.

Our study demonstrated the effective blockage of fungal ROS production by RB, PPADS and apyrase (Fig. 4c, d). The results suggest that eATP is a key signal for ROS mediating responses to the live bacterium. Based on the time courses of eATP release (Fig. 1d) and $\mathrm{H}_{2} \mathrm{O}_{2}$ production (Fig. 4d), the peak value of eATP level induced by the bacterium SB1 was detected earlier $(4 \mathrm{~h})$ than $\mathrm{H}_{2} \mathrm{O}_{2}$ production (12h). However, the full suppression of eATP in the co-culture by DPI (NADPH oxidase inhibitor) and VC (ROS scavenger) suggested that ROS generation also affected eATP levels (Fig. 7). In our previous studies, ROS generation has been induced to mediate the enhancement of HA production by abiotic elicitors including ultrasound stimulation [18], Triton X-100 treatment [24] and light/dark exposure [17]. Although our present results are still not sufficient to determine whether eATP acts as a signal upstream or downstream of ROS in the co-culture, eATP and ROS are necessary signal molecules involved in metabolite production in Shiraia under the elicitation.

Plant and animal cells have the ability to detect eATP through activation of receptors to trigger a transient increase in intracellular $\mathrm{Ca}^{2+}$ as key "danger" signals in wounding [5] and the inflammatory processes [3]. The activation of P2X and P2Y purinergic receptors by ATP triggered a transient increase in intracellular $\mathrm{Ca}^{2+}$ by promoting extracellular $\mathrm{Ca}^{2+}$ influx or endoplasmatic reticulum $\mathrm{Ca}^{2+}$ release in neural differentiation [37]. In Arabidopsis, DORN1, a lectin receptor kinase was bound to eATP with high affinity and required for the induced intracellular $\mathrm{Ca}^{2+}[6]$. Our data showed the accumulation of intracellular $\mathrm{Ca}^{2+}$ (Fig. 5) was observed after SB1 treatment for $30 \mathrm{~min}$. The application of nucleotide receptor antagonists (PPADS or RB) suppressed fully the SB1-activated $\mathrm{Ca}^{2+}$ accumulation (Fig. $5 \mathrm{~d}$ ), indicating the regulation role of eATP in the $\mathrm{Ca}^{2+}$ accumulation. In turn, the released eATP was completely blocked by $\mathrm{Ca}^{2+}$ membrane channel blocker $\mathrm{La}^{3+}$ and significantly decreased by $\mathrm{Ca}^{2+}$ chelator (Fig. 7). Although the strong calcium dependence for eATP production was revealed, current evidence is still insufficient to make a clear conclusion that eATP secretion is downstream of $\mathrm{Ca}^{2+}$ influx in the co-culture or vice versa. Furthermore, Song et al. (2006) reported that the eATP induced the accumulation of superoxide was dependent on cytosolic $\mathrm{Ca}^{2+}$ concentration in Arabidopsis [38]. ROS also mediated the cytosolic $\mathrm{Ca}^{2+}$ elevation by activating plasma membrane hyperpolarization-activated $\mathrm{Ca}^{2+}$ influx channels [39]. In present study, we found that the inhibition of ROS production by Vc or DPI did not affect $\mathrm{Ca}^{2+}$ accumulation (Fig. 6a), but chelation or block of $\mathrm{Ca}^{2+}$ remarkably decreased ROS production in co-culture (Fig. 6c, d). These results suggested that ROS generation might occur downstream of the $\mathrm{Ca}^{2+}$ influx in the co-culture (Fig. 11). In Shiraia sp. Slf14, the transcriptional levels of $\mathrm{Ca}^{2+}$ sensor-encoding genes (cam, can, and $c r z 1)$ and biosynthetic genes ( $p k s$, 


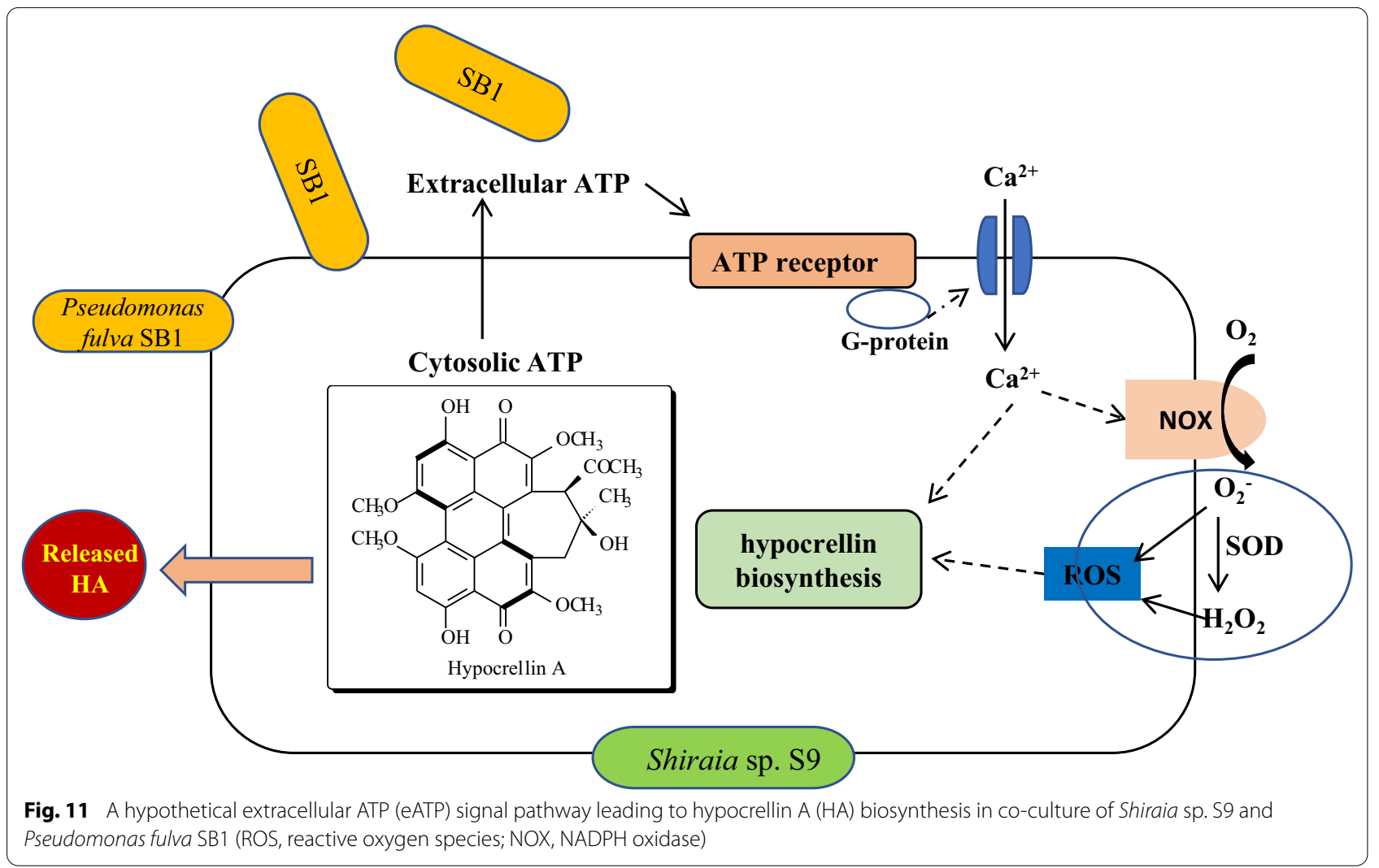

omef and hydroxylase) for HA was upregulated by $\mathrm{Ca}^{2+}$ induction [23]. In this study, the expressions of HA biosynthetical genes ( $P K S, F A D$, and Mono) were upregulated markedly in co-culture or by exATP at $100 \mu \mathrm{M}$ (Fig. 8). Both the expression of HA biosynthetic genes and the HA accumulation in the co-culture were significantly inhibited under the blocking of the eATP or $\mathrm{Ca}^{2+}$ signaling by $\mathrm{RB}$ or $\mathrm{La}^{3+}$, and the scavenge of ROS by Vc (Figs. 9 and 10). These results indicate that eATP can act as a signal message in the $\mathrm{Ca}^{2+}$-mediated signal transduction leading to the biosynthesis of HA in the coculture (Fig. 11).

\section{Conclusions}

We demonstrated that transient ATP release was an early event in the response of fungal host Shiraia sp. S9 to a fruiting body-associated bacterium $P$. fulva SB1. The eATP signal was sensitive to RB and PPADS and may act as DAMP signal associated with intimate bacterial-fungal interactions. eATP was closely linked to $\mathrm{Ca}^{2+}$ influx and ROS generation to become an essential early event in the activation of fungal conidiation and the elicitation of HA production. These small molecular signals could contribute to the bacterial-fungal communication leading to the transcript induction of HA biosynthetic genes. To the best of our knowledge, this study is the first to demonstrate the elevation of eATP by the interaction of bacteria and fungi. These findings increase our understanding of signal role of eATP in microbes and intimate bacterial-fungal interaction for developing co-culture strategy in the production of desired fungal metabolites.

\section{Materials and methods}

Strains, media, and culture conditions

Shiraia sp. S9 and the bacterium P. fulva SB1 were isolated from the fresh Shiraia fruiting bodies in our previous work [20] and deposited in China General Microbiological Culture Collection Center (registered as CGMCC16369 and CGMCC 13931 respectively). SB1 was stored in Luria-Bertani (LB) slant (pH7.2) at $4{ }^{\circ} \mathrm{C}$ and initially grown on LB medium in a Petri dish at $37^{\circ} \mathrm{C}$ for 2 days. S9 was kept on a potato dextrose agar (PDA) slant at $4{ }^{\circ} \mathrm{C}$ and initially grown on PDA medium in a Petri dish at $28^{\circ} \mathrm{C}$ for 10 days. As a preculture, $50-\mathrm{mL}$ of modified liquid medium $(100 \mathrm{~g} / \mathrm{L}$ potato, $20 \mathrm{~g} / \mathrm{L}$ starch, $4 \mathrm{~g} / \mathrm{L}$ $\mathrm{NaNO}_{3}, 1.5 \mathrm{~g} / \mathrm{L} \mathrm{KH}_{2} \mathrm{PO}_{4}, 0.5 \mathrm{~g} / \mathrm{L} \mathrm{CaCO}_{3}$ and $0.01 \mathrm{~g} / \mathrm{L} \mathrm{VB}_{1}$, $\mathrm{pH}$ 6.3) inoculated with $10^{7}$ spores $/ \mathrm{mL}$ was used. The preculture was maintained at $28{ }^{\circ} \mathrm{C}$ for 2 days with shaking at $150 \mathrm{rpm}$ and then transferred $(1 \mathrm{~mL})$ into a 150 $\mathrm{mL}$ flask containing $50 \mathrm{~mL}$ of the same liquid medium at 150 rpm and $28^{\circ} \mathrm{C}$ for 8 days. 


\section{Co-culture of Shiraia sp. S9 and P. fulva SB1}

Fungal-bacterial co-cultivation on PDA plates were performed as previously described [20]. In details, the S9 strain was initially grown on PDA for 8 days at $28^{\circ} \mathrm{C}$. A small piece of $S 9(5 \mathrm{~mm} \times 5 \mathrm{~mm})$ was placed in the center of a PDA plate $(10 \mathrm{~cm})$ and incubated at $28^{\circ} \mathrm{C}$ for 4 days in the dark. Then, $10 \mu \mathrm{L}$ of the SB1 suspension (co-cultivation) or fresh sterile LB broth (control) was streaked in two parallel straight lines, about $7 \mathrm{~cm}$ apart from each other (Fig. 1a). To establish the co-cultivation in Shiraia mycelium culture, live SB1 at 400 cells $/ \mathrm{mL}$ was added to 6-day-old culture and maintained at $150 \mathrm{rpm}$ and $28^{\circ} \mathrm{C}$ [20].

\section{Preparation of elicitors and inhibitor solutions}

To determine the source of eATP in the co-culture, we used the extracts of the bacterium SB1 or the fungal strain S9 as elicitors to induce eATP release from the culture. Bacterial cells (SB1) and cultural broth were harvested after $12 \mathrm{~h}$ by centrifugation at $12,000 \mathrm{rpm}$ for $10 \mathrm{~min}$. The supernatant was extracted by threefold volume of ethyl acetate and re-dissolved in ethanol as bacterial broth extracts (BBE). The crude SB1 polysaccharide (BPS) was prepared according to our previously described method [20]. For preparation of the fungal extracts, the cultural broth was collected from 6-day-old mycelium culture by filtration with 400-mesh filter membrane (Dongkang, Tianjin, China) and extracted by threefold volume of $95 \%$ ethanol. The precipitate was collected and dialyzed to remove small molecules $(<3,500 \mathrm{Da})$, and finally lyophilized to obtain the fungal polysaccharides (FPS). The ethyl acetate extracts of the cultural broth were evaporated in vacuo to afford a residue (FBE).

To determine the changes of eATP in the culture of S9 after the bacterial elicitation, the live SB1 (B, 400 cells/ $\mathrm{mL}$ ), autoclaved SB1 suspension (DB, 400 cells $/ \mathrm{mL}$ ), BPS $(100 \mathrm{mg} / \mathrm{L})$ and $\mathrm{BBE}(100 \mathrm{mg} / \mathrm{L})$ were added to 6-dayold culture of fungal S9, respectively. To determine the changes of eATP in the bacterial culture, FPS $(100 \mathrm{mg} / \mathrm{L})$, FBE $(100 \mathrm{mg} / \mathrm{L})$ and standard HA $(5 \mathrm{mg} / \mathrm{mL})$ were added to live SB1 ( 400 cells $/ \mathrm{mL}$ ) in $50 \mathrm{~mL}$ shake flasks filled with $10 \mathrm{~mL}$ modified liquid medium. eATP concentration was detected after $1 \mathrm{~h}$ of the treatment.

To determine the dependence of bacteria SB1 elicitation on eATP, some specific antagonists were applied to the cultures, i.e. RB (Yuanye Biotech., Shanghai, China) at $10 \mu \mathrm{M}$ as an inhibitor of eATP signal transduction across the plasma membrane, PPADS (Abcam, Cambridge, MA, USA) at $10 \mu \mathrm{M}$ as the purinoceptor inhibitor, and apyrase (Sigma-Aldrich, St Louis, MO, USA) at $2 \mathrm{U} / \mathrm{mL}$ as an enzyme for hydrolyzing ATP. These inhibitors and their dosages were chosen based on previous studies [40, 41]. The inhibitors were added to the culture at $1 \mathrm{~h}$ prior to the addition of SB1. Additional control experiments were conducted in the mycelium culture with a nonhydrolyzable form of ATP, ATP $\mathrm{S}$ (Sigma-Aldrich, St Louis, MO, USA) at $100 \mu \mathrm{M}$, and two hydrolyzed ATP derivatives, ADP and AMP (Yuanye Biotech., Shanghai, China) at $100 \mu \mathrm{M}$ to determine the effects of ATP hydrolysis on the elicitation.

\section{Detection of extracellular ATP}

The eATP concentration was determined by a fluorometric method using the luciferin-luciferase ATP assay kit (Beyotime Biotech., Haimen, Jiangsu, China) as reported by $\mathrm{Wu}$ et al. [41]. The fermentation broth $(500 \mu \mathrm{L})$ was collected from each of the shake flasks at selected time intervals for the luminance measure by a GloMax 20/20 luminometer (Promega, USA).

\section{Detection of ROS generation}

ROS generation in hyphae of Shiraia sp. S9 was detected by using DCFH-DA (Beyotime Biotech., Haimen, Jiangsu, China) under the fluorescence microscopy (BX51, Olympus, Tokyo, Japan) with excitation wavelength at $480 \mathrm{~nm}$ and emission wavelength at $520 \mathrm{~nm}$ [42]. The content of hydrogen peroxide $\left(\mathrm{H}_{2} \mathrm{O}_{2}\right)$ was measured as described previously [43]. To analysis the signaling role of ROS in the co-culture, $0.1 \mathrm{mM}$ Vc or $5 \mu \mathrm{M}$ DPI was added $1 \mathrm{~h}$ prior to the addition of SB1 in the culture.

\section{Measurement of intracellular $\mathrm{Ca}^{2+}$}

The change of intracellular $\mathrm{Ca}^{2+}$ concentration in fungal pellets was detected by the $\mathrm{Ca}^{2+}$-sensitive probe Fluo3-AM (Beyotime Biotech., Haimen, Jiangsu, China). The fungal pellets were incubated at $4{ }^{\circ} \mathrm{C}$ for $2 \mathrm{~h}$ in PBS containing $0.2 \mathrm{mM} \mathrm{CaCl}_{2}$ and $5 \mu \mathrm{M}$ Fluo-3-AM [40]. Subsequently, the pellets were incubated in the fungal medium for another $2 \mathrm{~h}$, and then subjected to various treatments. After the treatments, the pellets were collected and photographed by fluorescence microscopy (BX51, Olympus, Tokyo, Japan) with excitation wavelength at $480 \mathrm{~nm}$ and emission wavelength at $515 \mathrm{~nm}$. The integration of fluorescence intensity was defined as the relative intracellular $\mathrm{Ca}^{2+}$ concentration level [40]. $\mathrm{Ca}^{2+}$ chelator EGTA at $5 \mathrm{mM}$ and membrane channel blocker $\mathrm{La}^{3+}$ (with $\mathrm{LaCl}_{3}$ ) at $2 \mathrm{mM}$ were applied to determine the signaling role of $\mathrm{Ca}^{2+}$ in the co-culture [41]. The inhibitors were added $1 \mathrm{~h}$ prior to the addition of SB1 in the culture.

\section{Quantification of conidia and HA production}

The conidia were collected in sterile water and quantified by hemocytometer. The intracellular and extracellular HA were extracted based on our previous report [24]. HPLC analysis was carried out in a reverse-phase Agilent 1260 HPLC system (Agilent Co., Wilmington, DE, USA) 
with Agilent HC-C18 column $(250 \mathrm{~mm} \times 4.6 \mathrm{~mm})$. HA was quantified with genuine standards (Chinese National Compound Library, Shanghai, China).

\section{Quantitative real-time polymerase chain reaction (qRT-PCR) analysis}

The primer sequences of HA biosynthesis related genes and $18 \mathrm{~S}$ ribosomal RNA as internal reference gene were listed in Additional file 1: Table S1. The qRT-PCR was performed according to the method described in our previous study [44]. The transcriptional expression levels of genes were calculated from cycle threshold values by using the $2^{-\triangle \triangle \mathrm{CT}}$ method described by Zhang et al. [45].

\section{Statistical analysis}

Student's $t$-test was used as a significance test to compared the means between two groups. One-way analysis of variance (ANOVA) was used to assess the significance of differences of the means among multiple groups. All results are expressed as Mean \pm Standard Deviation (SD). The level of significance was set at $p<0.05$.

\section{Supplementary Information}

The online version contains supplementary material available at https://doi. org/10.1186/s12934-021-01637-9.

Additional file 1: Table S1. Primers and relevant information of reference and target genes. F: forward primer, R: reverse primer.

\section{Acknowledgements}

Not applicable.

\section{Authors' contributions}

JWW and XPL conceived the study and participated in its design. XPL, LLZ and YHG undertook experiments and data analysis. JWW and XPL drafted the manuscript. JWW supervised the research and revised the paper. All authors discussed the results and commented. All authors read and approved the final manuscript.
\end{abstract}

\section{Funding}

This work was supported by the National Natural Science Foundation of China (Nos. 82073955 and 81773696) and the Priority Academic Program Development of the Jiangsu Higher Education Institutes (PAPD).

\section{Availability of data and materials}

All data generated or analyzed during this study are included in this published article and its Additional files.

\section{Declarations}

\section{Ethics approval and consent to participate}

Not applicable.

\section{Consent for publication}

Not applicable.

\section{Competing interests}

The authors declare that they have no competing interests.
Received: 26 April 2021 Accepted: 16 July 2021

Published online: 23 July 2021

\section{References}

1. Gordon JL. Extracellular ATP: effects, sources and fate. Biochem J. 1986;233:309-19.

2. Buvinic S, Almarza G, Bustamante M, Casas M, López J, Riquelme M, et al. ATP released by electrical stimuli elicits calcium transients and gene expression in skeletal muscle. J Biol Chem. 2009;284:34490-505.

3. Bours MLL, Swennen ELR, Di Virgilio F, Cronstein BN, Dagnelie PC. Adenosine 5'-triphosphate and adenosine as endogenous signaling molecules in immunity and inflammation. Pharmacol Therapeut. 2006;112:358-404.

4. Khakh BS, Burnstock G. The double life of ATP. Sci Am. 2009;301:84-92.

5. Tanaka K, Gilroy S, Jones AM, Stacey G. Extracellular ATP signaling in plants. Trends Cell Biol. 2010;20:601-8.

6. Choi JM, Tanaka K, Cao YR, Qi Y, Qiu J, Liang Y, et al. Identification of a plant receptor for extracellular ATP. Science. 2014;343:290-4.

7. Clark GB, Morgan RO, Fernandez MP, Salmi ML, Roux SJ. Breakthroughs spotlighting roles for extracellular nucleotides and apyrases in stress responses and growth and development. Plant Sci. 2014;225:107-16.

8. Mempin R, Tran H, Chen CN, Gong H, Ho KK, Lu SW. Release of extracellular ATP by bacteria during growth. BMC Microbiol. 2013;13:301.

9. Ding Q, Quah SY, Tan KS. Secreted adenosine triphosphate from Aggregatibacter actinomycetemcomitans triggers chemokine response. Mol Oral Microbiol. 2016;31:423-34.

10. Proietti M, Perruzza L, Scribano D, Pellegrini G, D'Antuono R, Strati F, et al. ATP released by intestinal bacteria limits the generation of protective $\lg A$ against enteropathogens. Nat Commun. 2019;10:250.

11. Ding QF, Tan KS. The danger signal extracellular ATP is an inducer of Fusobacterium nucleatum biofilm dispersal. Front Cell Infect Microbiol. 2016;6:155.

12. Medina-Castellanos E, Esquivel-Naranjo EU, Heil M, Herrera-Estrella A. Extracellular ATP activates MAPK and ROS signaling during injury response in the fungus Trichoderma atroviride. Front Plant Sci. 2014;5:00659.

13. Medina-Castellanos E, Villalobos-Escobedo JM, Riquelme M, Read ND, Abreu-Goodger C, Herrera-Estrella A. Danger signals activate a putative innate immune system during regeneration in a filamentous fungus. PLoS Genet. 2018;14:1007390.

14. Li M, Chen Y, Wu SJ, Tang Y, Deng Y, Yuan JL, et al. TmcN is involved in ATP regulation of tautomycetin biosynthesis in Streptomyces griseochromogenes. Biochem Bioph Res Co. 2016;478:221-6.

15. Mulrooney CA, O'Brien EM, Morgan BJ, Kozlowski MC. Perylenequinones: isolation, synthesis, and biological activity. Eur J Org Chem. 2012;21:3887-904.

16. Hudson JB, Zhou J, Chen J, Harris L, Yip L, Towers GHN. Hypocrellin, from Hypocrella bambuase, is phototoxic to human immunodeficiency virus. Photochem Photobiol. 1994;60:253-5.

17. Sun CX, Ma YJ, Wang JW. Improved hypocrellin A production in Shiraia bambusicola by light-dark shift. J Photochem Photobiol B. 2018;182:100-7.

18. Sun CX, Ma YJ, Wang JW. Enhanced production of hypocrellin A by ultrasound stimulation in submerged cultures of Shiraia bambusicola. Ultrason Sonochem. 2017;38:214-24.

19. Ma YJ, Zheng LP, Wang JW. Bacteria associated with Shiraia fruiting bodies influence fungal production of hypocrellin A. Front Microbiol. 2019;10:2023

20. Ma $Y J$, Zheng LP, Wang JW. Inducing perylenequinone production from a bambusicolous fungus Shiraia sp. S9 through co-culture with a fruiting body-associated bacterium Pseudomonas fulva SB1. Microb Cell Fact. 2019;18:121.

21. Bodin P, Burnstock G. Purinergic signalling: ATP release. Neurochem Res. 2001;26:959-69.

22. Wu SJ, Siu KC, Wu JY. Involvement of anion channels in elicitorinduced ATP efflux in Salvia miltiorrhiza hairy roots. J Plant Physiol. 2011;168:128-32.

23. Liu B, Bao JY, Zhang ZB, Yan RM, Wang Y, Yang HL, et al. Enhanced production of perylenequinones in the endophytic fungus Shiraia sp. Slf14 by 
calcium/calmodulin signal transduction. Appl Microbiol Biotechnol. 2018;102:153-63.

24. Lei XY, Zhang MY, Ma YJ, Wang JW. Transcriptomic responses involved in enhanced production of hypocrellin A by addition of Triton X-100 in submerged cultures of Shiraia bambusicola. J Ind Microbiol Biotechnol. 2017:44:1415-29.

25. Arora D, Gupta P, Jaglan S, Roullier C, Grovel O, Bertrand S. Expanding the chemical diversity through microorganisms co-culture: current status and outlook. Biotechnol Adv. 2020. https://doi.org/10.1016/j.biotechadv. 2020.107521.

26. Shang Z, Salim AA, Capon RJ. Chaunopyran A. co-cultivation of marine mollusk-derived fungi activates a rare class of 2-alkenyl-tetrahydropyran. J Nat Prod. 2017:80:1167-72.

27. Schroeckh V, Scherlach K, Nüetzmann HW, Shelest E, Schmidt-Heck W, Schuemann J, et al. Intimate bacterial-fungal interaction triggers biosynthesis of archetypal polyketides in Aspergillus nidulans. Proc Natl Acad Sci USA. 2009;106:14558-63.

28. Nützmann HW, Reyes-Dominguez Y, Scherlach K, Schroeck V, Horn F, Gacek A, et al. Bacteria-induced natural product formation in the fungus Aspergillus nidulans requires Saga/Ada-mediated histone acetylation. Proc Natl Acad Sci USA. 2011;108:14282-7.

29. Ivanova EP, Alexeeva YV, Pham DK, Wright JP, Nicolau DV. ATP level variations in heterotrophic bacteria during attachment on hydrophilic and hydrophobic surfaces. Int Microbiol. 2006;9:37-46.

30. Iwase T, Shinji H, Tajima A, Sato F, Tamura T, Iwamoto T, et al. Isolation and identification of ATP-secreting bacteria from mice and humans. J Clin Microbiol. 2010:48:1949-51.

31. Hironaka I, Iwase T, Sugimoto S, Okuda K, Tajima A, Yanaga K, et al. Glucose triggers ATP secretion from bacteria in a growth-phase-dependent manner. Appl Environ Microbiol. 2013;79:2328-35.

32. Atarashi K, Nishimura J, Shima T, Umesaki Y, Yamamoto M, Onoue $M$, et al. ATP drives lamina propria $T(H) 17$ cell differentiation. Nature. 2008:455:808-12.

33. Zhong XT, Malhotra R, Guidotti G. ATP uptake in the Golgi and extracellular release require $\mathrm{Mcd} 4$ protein and the vacuolar $\mathrm{H}^{+}$-ATPase. J Biol Chem. 2003;278:33436-44

34. Koshlukova SE, Lloyd TL, Araujo MWB, Edgerton M. Salivary histatin 5 induces non-lytic release of ATP from Candida albicans leading to cell death. J Biol Chem. 1999;274:18872-9.
35. Jakubowski H, Goldman E. Evidence for cooperation between cells during sporulation of the yeast Saccharomyces cerevisiae. Mol Cell Biol. 1988:8:5166-78.

36. Miao L, Kwong TFN, Qian PY. Effect of culture conditions on mycelial growth, antibacterial activity, and metabolite profiles of the marinederived fungus Arthrinium c.f. saccharicola. Appl Microbiol Biotechnol. 2006;72:1063-73.

37. Glaser T, Resende RR, Ulrich H. Implications of purinergic receptormediated intracellular calcium transients in neural differentiation. Cell Commun Signal. 2013;11:12.

38. Song CJ, Steinebrunner I, Wang XZ, Stout SC, Roux SJ. Extracellular ATP induces the accumulation of superoxide via NADPH oxidases in Arabidopsis. Plant Physiol. 2006;140:1222-32.

39. Demidchik V, Shang ZL, Shin R, Thompson E, Rubio L, Laohavisit A, et al. Plant extracellular ATP signalling by plasma membrane NADPH oxidase and $\mathrm{Ca}^{2+}$ channels. Plant J. 2009:58:903-13.

40. Wu SJ, Wu JY. Extracellular ATP-induced NO production and its dependence on membrane $\mathrm{Ca}^{2+}$ flux in Salvia miltiorrhiza hairy roots. J Exp Bot. 2008:59:4007-16.

41. Wu SJ, Liu YS, Wu JY. The signaling role of extracellular ATP and its dependence on $\mathrm{Ca}^{2+}$ flux in elicitation of Salvia miltiorrhiza hairy root cultures. Plant Cell Physiol. 2008:49:617-24.

42. You BJ, Lee MH, Tien N, Lee MS, Hsieh HC, Tseng LH, et al. A novel approach to enhancing ganoderic acid production by Ganoderma lucidum using apoptosis induction. PLoS One. 2013;8:53616.

43. Mirshekari A, Madani B, Golding JB. Aloe vera gel treatment delays postharvest browning of white button mushroom (Agaricus bisporus). J Food Meas Charact. 2019;13:1250-6.

44. Ma YJ, Lu CS, Wang JW. Effects of 5-azacytidine on growth and hypocrellin production of Shiraia bambusicola. Front Microbiol. 2018;9:2508.

45. Zhang J, Zhu LY, Chen HY, Li M, Zhu XJ, Gao Q, et al. A polyketide synthase encoded by the gene An15g07920 is involved in the biosynthesis of ochratoxin A in Aspergillus niger. J Agric Food Chem. 2016;64:9680-8.

\section{Publisher's Note}

Springer Nature remains neutral with regard to jurisdictional claims in published maps and institutional affiliations.
Ready to submit your research? Choose BMC and benefit from:

- fast, convenient online submission

- thorough peer review by experienced researchers in your field

- rapid publication on acceptance

- support for research data, including large and complex data types

- gold Open Access which fosters wider collaboration and increased citations

- maximum visibility for your research: over 100M website views per year

At $\mathrm{BMC}$, research is always in progress.

Learn more biomedcentral.com/submissions 